\title{
Predicting hospital length of stay for geriatric and adult patients with schizophrenia
}

\author{
Zahinoor Ismail*1,2, Tamara Arenovich ${ }^{3}$, Charlotte Grieve ${ }^{4}$, Peggie Willett ${ }^{4}$, Donald Addington ${ }^{5}$, Tarek K Rajji ${ }^{2}$, \\ Benoit H. Mulsant ${ }^{2,4}$ \\ ${ }^{1}$ Departments of Psychiatry and Neurology, Hotchkiss Brain Institute, University of Calgary, Calgary, Alberta, Canada \\ ${ }^{2}$ Department of Psychiatry, University of Toronto, Toronto, Ontario, Canada \\ ${ }^{3}$ Biostatistical Consulting Service, Clinical Research Department, Centre for Addiction and Mental Health; Division of \\ Biostatistics, Dalla Lana School of Public Health, University of Toronto, Toronto, Ontario, Canada \\ ${ }^{4}$ Decision Support, Centre for Addiction and Mental Health, Toronto, Ontario, Canada \\ ${ }^{5}$ Department of Psychiatry, University of Calgary, Calgary, Alberta, Canada
}

Received: October 20, 2014

DOI: $10.5430 /$ jha.v4n2p15
Accepted: December 29, 2014 Online Published: January 27, 2015

URL: http://dx.doi.org/10.5430/jha.v4n2p15

\begin{abstract}
Objective: To determine predictors of psychiatric hospital length of stay (LOS) for geriatric and adult patients with schizophrenia admitted to inpatient beds, that could be determined within 72 hours of hospitalization.

Methods: General linear models were used to identify and compare predictors of LOS for 187 geriatric patients and 881 general adult patients with schizophrenia admitted to a large urban mental health centre between 2005 and 2010. Demographic and clinical information were obtained from the Resident Assessment Inventory - Mental Health (RAI).

Results: Increased dependence score on the Instrumental Activities of Daily Living scale predicted longer LOS in general adult but not in geriatric schizophrenia patients. Predictors of longer LOS irrespective of age group included recent psychiatric admissions, living alone and incapacity to make treatment decisions.

Conclusions: Specific clinical characteristics are associated with longer hospitalization in patients with schizophrenia. Addressing these factors early on in the admission may result in shorter LOS and better use of resources.
\end{abstract}

Key Words: Hospital length of stay, Schizophrenia, Service delivery, Capacity, Function, Instrumental activities of daily living

\section{Introduction}

Schizophrenia is a chronic and debilitating illness, and this diagnosis predicts longer cumulative hospital lengthy of stay (LOS).$^{[1]}$ People with schizophrenia disproportionately comprise long stay psychiatric hospitalizations. ${ }^{[2]}$ In comparison to affective disorders, schizophrenia is associated with longer psychiatric LOS. ${ }^{[3]}$ Poor functioning in schizophrenia has also been associated with longer psychiatric LOS. ${ }^{[3,4]}$ With the aging of the population, the num- ber of older patients with schizophrenia is expected to increase markedly during the next decade. By $2025,20 \%$ of patients with schizophrenia will be age 65 or older, but this population remains under-studied. ${ }^{[5]}$ Late-life or geriatric schizophrenia (LLS) has been associated with an increased use of inpatient services in comparison to schizophrenia in younger patients ${ }^{[6,7]}$ and in comparison to late-life bipolar disorder. ${ }^{[8]}$ While geriatric psychiatry hospitalizations can be lengthy, there is a lack of empirical data guiding the

*Correspondence: Zahinoor Ismail MD FRCPC; Email: zahinoor@gmail.com; Address: 140329 St NW Calgary Alberta, Canada. 
use of these highly specialized beds and services in older patients with schizophrenia. A study of overall determinants of psychiatric hospital LOS found that ECT, higher Brief Psychiatric Rating Scale positive symptom scores, falls, pharmacology complications, multiple prior psychiatric hospitalizations, and requiring court proceedings to provide medications or continue hospitalization were predictors of longer stays for geriatric patients in general. ${ }^{[9]}$ While other studies have characterized schizophrenia in late life ${ }^{[10-12]}$ and assessed predictors of $\operatorname{LOS},{ }^{[13-16]}$ to our knowledge none have assessed predictors of LOS in LLS patients in comparison to general adult schizophrenia patients to determine age-specific predictors, for both the younger and older groups. We therefore analyzed a large database to characterize younger and older patients with schizophrenia. We assessed geriatric patients who were hospitalized for the treatment of schizophrenia and identified predictors of LOS. To assess whether these predictors were specific to late life, we also analyzed and compared similar data obtained in younger patients with schizophrenia to determine predictors of LOS in this population as well.

\section{Methods}

\subsection{Setting}

The Centre for Addiction and Mental Health (CAMH) is a 538-bed academic specialty hospital that offers both secondary and tertiary services to patients with mental and substance-use disorders. CAMH is located in downtown Toronto, Ontario. It is Canada's largest mental health and addictions teaching hospital and has specific programs for various illnesses and age groups. The two geriatric inpatient units at CAMH comprise 48 beds, more than half of the 94 specialized geriatric psychiatry beds in the Toronto, a city with over 2.6 million people. Patients admitted to these two units are over 60 years of age and are primarily diagnosed with dementia, mood disorders or schizophrenia. They are admitted directly from CAMH emergency department, upon transfer from other units at $\mathrm{CAMH}$, upon referral from other hospitals, or upon direct referral from CAMH outpatient clinics or from the community for "scheduled admissions". The adult schizophrenia inpatient units at CAMH comprise 233 beds for adult patients with schizophrenia admitted following pathways similar to geriatric patients.

\subsection{Assessment instrument}

All patients admitted to a CAMH inpatient unit are assessed with the Resident Assessment Instrument-Mental Health (RAI-MH) on admission and at discharge, as well as quarterly if they are in hospital for more than three months. The RAI-MH is a patient-focused, multidimensional inventory designed to be part of a larger integrated health information system. ${ }^{[17]}$ It allows for the systematic assessment of patient characteristics and it has been shown to be a valid and reliable method to characterize patients. ${ }^{[18]}$ It has been used to predict outcomes in geriatric psychiatry patients. ${ }^{[19-21]}$ Its use has been mandated by the province of Ontario for all adult inpatient mental health beds. The RAI-MH provides extensive data including demographic information, language, education, reasons for admission, residential status prior to admission, mental health service history, inpatient status, capacity, forensic history, mental state, function, self-care, cognition, service utilization and psychiatric diagnosis. At CAMH the RAI-MH is completed via an online tool by members of the interprofessional team, with psychiatric nurses providing the majority of the required information. All staff are trained in the RAI-MH domains for which they are responsible and data consistency is monitored through a Decision Support office at CAMH.

\subsection{Database creation}

This analysis focused on data for all patients admitted to and discharged from the geriatric psychiatry units comprising 48 beds between January 1, 2005 and December 31, 2010 and for adult patients admitted to and discharged from 3 representative general adult schizophrenia units comprising 62 beds over the same time period. Data were anonymized by removing the patients' name and medical record number from the data file. The anonymized final data file contained the following information for each patient included in the analysis: LOS, patient age, diagnosis and RAI outcome data. RAI outcome data included clinical information such as gender; threat to others; inability to care for self; involvement with criminal justice system; living arrangements (alone vs. not alone); number of recent psychiatric admissions; age at first hospitalization; inpatient status (voluntary $v s$. involuntary); incapacity; insight; history of falls; medication refusal; use of control interventions (physical restraint or seclusion, close/constant observation); close or constant observation; available social supports; total days in alternative level of care; as well as measures of Activities of Daily Living (ADL); Instrumental ADLs (IADL); cognitive performance; depression; positive symptoms; negative symptoms; aggressive behaviour; medical burden; and pain. Patients with a diagnosis of schizophrenia or related disorders were included in this analysis.

\subsection{Patients}

All admissions over the 6-year time period were assessed. For patients with multiple admissions, one of the admissions was randomly selected for inclusion in the analysis. This was necessary in order to meet the independence of observations assumption that underlies the statistical methodology. Twenty one patients whose multiple admissions spanned different inpatient services were omitted. Four patients with length of stay shorter than three days were excluded from the analysis as only a short-stay RAI was completed, which did not have the full complement of clinical information in the full RAI-MH. Based on a diagnosis of schizophrenia 
or related disorder 1,068 of these patients were considered for inclusion in the analysis: 187 geriatric patients and 991 adult patients. Those who were missing data on any one of the predictor variables included in the analysis were excluded. This resulted in a final sample of 187 patients included in the geriatric schizophrenia group and 881 in the adult schizophrenia group.

This study was approved by the CAMH research ethics board and exempted from the requirement for informed consent because the study involved de-identified data acquired during routine care.

\subsection{Data analysis}

Data analysis was conducted using SAS/STAT software, v.9.1.3 of the SAS System for Windows (Copyright 20022003 SAS Institute Inc., Cary, NC, USA). A series of clinically relevant predictors were selected, and the set was reduced through preliminary exploratory analyses ( $t$-tests, chi-square tests, and ANOVA were used as appropriate).

A natural-logarithm transformation was applied to LOS (defined as the number of days between discharge and admission) prior to testing in order to improve its distributional properties, to better meet the statistical assumptions underlying the approach. To investigate the characteristics associated with LOS among geriatric schizophrenia inpatients, a series of general linear models were conducted. The analysis incorporates the values of the clinical variables at time of admission, collected over the first 72 hours. While discharge information was also available for most of these variables, these characteristics would be of limited value in predicting LOS among future patients, as they cannot, by definition, be known until the end of each patient's stay. Thus, discharge disposition was excluded from the analysis due to the uncertainty of determining discharge destination for patients with changing socioeconomic and clinical status over the course of the hospitalization. The one exception to this rule is incapacity: for this analysis, patients are defined to have incapacity if any of the RAI-MH incapacity items (treatment, property, disclosure of health information, or having a substitute decision maker) is endorsed at either admission or discharge, due to the fact that capacity assessment can be done but is sometimes overlooked during the first 72 hours of hospitalization when safety is typically prioritized.

Predictors that were not associated with LOS were excluded using a purposeful selection of covariates approach. Unnecessary predictors were excluded in order to enhance the parsimony of the model. Two-way interactions between study group and all of the predictors were investigated, and only those found to achieve or approach statistical significance were retained in the final model. All tests were two-tailed and carried out at an alpha level of 0.05 .

\section{Results}

\subsection{Descriptive analysis}

Group demographics are shown in Table 1. The mean $S D$ LOS for geriatric schizophrenia patients was 84.1 (108.2) with a median (range) of 47.0 (4-861); the mean SD LOS for general adult schizophrenia patients was 48.1 days (67.6) with a median (range) of 22.0 days (3-722). Among the geriatric patients, $118(63 \%)$ were female compared to 269 (31\%) of the adult patients. The mean $S D$ age was 70.3 (7.2) for the geriatric patients and 42.3 (11.3) for the adult patients.

\subsection{Predictive analysis}

Table 2 describes the results of the reduced general linear model comparing geriatric to adult schizophrenia patients. The interpretation of group effects and parameter estimates is different than in a standard linear model due to the logtransformation of the outcome variable. Instead of obtaining beta coefficients, which can be used to estimate of the difference between group means, estimates of the ratios of the geometric means of patients across levels of each predictor variable are obtained. These ratios and corresponding length of stay geometric means are summarized in Tables 3 and 4.

At a mean level of all additional factors in the model, geriatric schizophrenia patients had a greater LOS than general adult schizophrenia patients. On average, geriatric patients had a LOS $48 \%$ longer than the LOS of adult patients $(95 \%$ CI: $17 \%-88 \%$ ).

The only predictor of LOS that varied across the adult and geriatric groups was IADL impairment, which predicted LOS in general adult but not in geriatric schizophrenia patients. Incapacity, number of recent psychiatric admissions and living alone also significantly affected LOS, but the nature of these effects did not vary across the two study groups.

IADL impairment had a different effect among geriatric and general adult patients with schizophrenia. IADL scores were not associated with LOS among geriatric patients, but greater IADL impairment was associated with longer LOS among general adult patients. For every unit increase in IADL impairment, LOS increased on average by $3 \%$ among adult patients (95\% CI: $2 \%-4 \%$ ). Among patients with low IADL impairment (1 SD or more below the sample mean), geriatric patients stayed on average $81 \%$ longer than adult patients (95\% CI: 29\%-155\%). At average IADL function (within $1 S D$ of sample mean), geriatric patients stayed on average $48 \%$ longer than adult patients (95\% CI: 17\%-88\%). However, at high IADL impairment (i.e., 1 SD or more above the sample mean), the differences in LOS between geriatric and adult patients lost statistical significance: geriatric patients stayed on average only $21 \%$ longer than adult patients (95\% CI: $2 \%-50 \%)$. 
Table 1: Group demographics: Continuous measures are summarized by their mean and standard deviation, while categorical measures are reported as $\mathrm{n}(\%)$

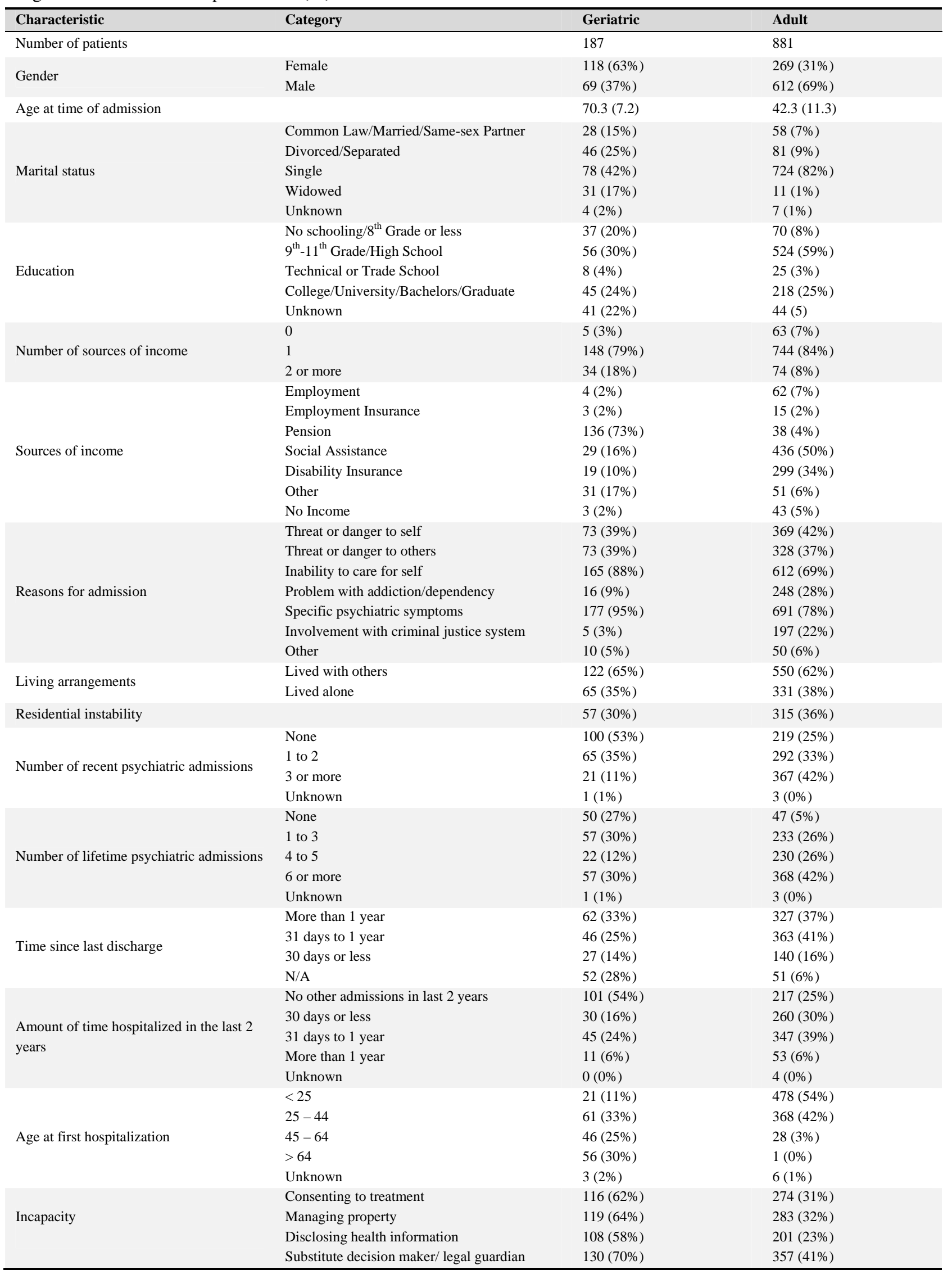


Table 2: Predictor of length of stay among adult and geriatric patients with schizophrenia - overall model

\begin{tabular}{lll}
\hline Predictor & F, df & Statistical Significance \\
\hline Overall Model & $\mathrm{F}=23.40, \mathrm{df}=10,1034$ & $p<.0001$ \\
Study group (Geriatric vs. Adult) & $\mathrm{F}=11.65, \mathrm{df}=1,1034$ & $p=.0007$ \\
Gender & $\mathrm{F}=2.75, \mathrm{df}=1,1034$ & $p=.0976$ \\
Reasons for admission - Involved with criminal justice system & $\mathrm{F}=12.26, \mathrm{df}=1,1034$ & $p=.0005$ \\
Lives alone & $\mathrm{F}=5.73, \mathrm{df}=1,1034$ & $p=.0168$ \\
Number of recent psychiatric admissions & $\mathrm{F}=3.48, \mathrm{df}=2,1034$ & $p=.0310$ \\
Incapacity & $\mathrm{F}=54.55, \mathrm{df}=1,1034$ & $p<.0001$ \\
IADL score & $\mathrm{F}=13.83, \mathrm{df}=1,1034$ & $p=.0002$ \\
Presence of any pain & $\mathrm{F}=3.61, \mathrm{df}=1,1034$ & $p=.0576$ \\
Study group $\times$ IADL & $\mathrm{F}=6.04, \mathrm{df}=1,1034$ & $p=.0141$ \\
\hline
\end{tabular}

IADL: Instrumental activities of daily living

Table 3: Predictors of length of stay among adult and geriatric patients with schizophrenia - parameter estimates

\begin{tabular}{|c|c|c|c|}
\hline Effect & Comparison & LOS Ratio & $\begin{array}{lc}95 \% \quad \text { CI } & \text { for } \\
\text { LOS } & \text { Ratio }\end{array}$ \\
\hline Study group ${ }^{*}$ & geriatric relative to adult & 1.48 & $(1.17,1.88)$ \\
\hline Study group $^{* *}$ - among subjects with low IADL (1 SD below mean) & geriatric relative to adult & 1.81 & $(1.29,2.55)$ \\
\hline Study group ${ }^{* *}$ - among subjects with average IADL (mean) & geriatric relative to adult & 1.48 & $(1.17,1.88)$ \\
\hline Study group ${ }^{* *}$ - among subjects with high IADL (1 SD above mean) & geriatric relative to adult & 1.21 & $(0.98,1.50)$ \\
\hline Gender & female relative to male & 1.12 & $(0.98,1.29)$ \\
\hline Involved with criminal justice system & involved relative to not involved & 0.74 & $(0.63,0.88)$ \\
\hline Lives alone & yes relative to no & 1.18 & $(1.03,1.35)$ \\
\hline \multirow{2}{*}{ Number of recent psychiatric admissions } & $1-2$ relative to none & 1.07 & $(0.91,1.25)$ \\
\hline & 3 or more relative to none & 1.24 & $(1.05,1.46)$ \\
\hline Incapacity & yes relative to no & 1.70 & $(1.47,1.95)$ \\
\hline IADL & 1 point increase & 1.02 & $(1.01,1.03)$ \\
\hline IADL $^{* *}$ - among adult patients & 1 point increase & 1.03 & $(1.02,1.04)$ \\
\hline $\mathrm{IADL}^{* *}$ - among geriatric patients & 1 point increase & 1.01 & $(0.99,1.02)$ \\
\hline Pain Scale (any pain y/n) & yes relative to no & 0.83 & $(0.68,1.01)$ \\
\hline
\end{tabular}

Note. IADL: Instrumental Activities of Daily Living; ${ }^{*}$ at mean level of IADL score and averaged over all levels of all remaining predictors; ${ }^{* *}$ averaged over all levels of all predictors not involved in the interaction

The remaining effects were not influenced by study group (i.e., the predictors listed below influence LOS equally among geriatric and adult schizophrenia patients). Patients living alone stayed on average $18 \%$ longer (95\% CI: $3 \%$ $35 \%)$ than those not living alone. Patients with 3 or more recent admissions stayed on average $24 \%$ longer (95\% CI: $5 \%-46 \%$ ) than those with no recent psychiatric admissions. Patients with any incapacity stayed on average $70 \%$ longer (95\% CI: 47\%-95\%) than those with no incapacities. Patients involved with the criminal justice system stayed on average only $74 \%$ as long as those not involved with the criminal justice system (95\% CI: 63\%-88\%).

\section{Discussions}

We have found median LOS is $56 \%$ longer in geriatric versus adult schizophrenia patients. This finding is consistent

Published by Sciedu Press with our previous study demonstrating that the characteristics of mood disorders in late life are different from those for younger populations. ${ }^{[20]}$

This difference in length of stay between groups may be explained by characteristics of the populations captured by the RAI-MH. Our model also suggests predictors of longer LOS in adult versus geriatric schizophrenia patients as well as specific predictors of longer LOS in schizophrenia patients as a whole. IADL scores have a different impact on LOS in adult patients than in geriatric patients, while living arrangements, number of recent psychiatric admissions, incapacity, involvement in the criminal justice system and pain all appear to have similar effects across schizophrenia age groups.

Function at admission is predictive of LOS in general adult 
schizophrenia patients, with greater IADL dependency predicting longer LOS. For IADL scores $1 S D$ above the mean, adult LOS was not statistically different from geriatric LOS. Functional impairment in schizophrenia has been well described in a study demonstrating significant IADL impairment in schizophrenia versus healthy matched controls. ${ }^{[22]}$ In a clinical population, a comparison of elderly patients with schizophrenia-schizoaffective disorder $(\mathrm{n}=$ 55), bipolar disorder $(\mathrm{n}=39)$ and depression $(\mathrm{n}=90)$, the schizophrenia-schizoaffective disorder group had poorer functioning especially the domains of self-care and community living skills..$^{[23]}$ An Israeli study of 81 acute care general adult patients with schizophrenia generated a predictive model of IADL performance using clinical and demographic information. In this model, a total variance of $53.5 \%$ consisted of executive functioning $(21 \%)$, memory and abstract thinking (13.5\%), negative symptoms (13\%), age of illness onset and years of education $(8 \%)^{[24]}$ demon- strating the multi-factorial contributors to functional impairment in schizophrenia. In a Japanese study of 217 inpatient and community dwelling elderly patients with schizophrenia, total needs of care were greater among patients with poor IADL self-performance. ${ }^{[25]}$ In another Japanese study assessing factors associated with long hospital LOS on geriatric medicine wards, IADL impairment, and most significantly medication management, was associated with longer LOS. ${ }^{[26]}$ Instrumental activities of daily living on the RAI include meal preparation, managing medications, independent transportation, managing finances, telephone use and stamina. Impairment in these functions may result in greater difficulty finding housing and living independently. However, an intervention study of personalized in-home nursing care plans demonstrated efficacy in improving function at home in adult patients with schizophrenia, ${ }^{[27]}$ demonstrating that IADLs can be modifiable in this patient population.

Table 4: Predictor of length of stay among adult and geriatric patients with schizophrenia - geometric LS means

\begin{tabular}{|c|c|c|c|c|c|}
\hline Effect & Level & $\begin{array}{l}\text { Geometric } \\
\text { LS-Mean }\end{array}$ & Ratio of Means* & 95\% CI of Ratio & $\begin{array}{l}\text { Statistical } \\
\text { Significance }\end{array}$ \\
\hline Study group ${ }^{* *}$ & $\begin{array}{l}\text { Adult }^{*} \\
\text { Geriatric }\end{array}$ & $\begin{array}{l}22.76 \\
33.75\end{array}$ & 1.48 & $(1.17,1.88)$ & $p=.0011$ \\
\hline $\begin{array}{l}\text { Study group } \\
\text { IADL } \text { scores ( } 1 S D \text { or more below mean) }\end{array}$ & $\begin{array}{l}\text { Adult }^{*} \\
\text { Geriatric }\end{array}$ & $\begin{array}{l}17.48 \\
31.67\end{array}$ & 1.81 & $(1.29,2.55)$ & $p=.0007$ \\
\hline $\begin{array}{l}\text { Study group }{ }^{* * * *} \text { - among patients with normal } \\
\text { IADL scores (within } 1 S D \text { of mean) }\end{array}$ & $\begin{array}{l}\text { Adult } \\
\text { Geriatric }\end{array}$ & $\begin{array}{l}22.77 \\
33.75\end{array}$ & 1.48 & $(1.17,1.88)$ & $p=.0011$ \\
\hline $\begin{array}{l}\text { Study group } \\
\text { IADL } \text { - among patients with high } \\
\text { scores (1 SD or more above mean) }\end{array}$ & $\begin{array}{l}\text { Adult } \\
\text { Geriatric }\end{array}$ & $\begin{array}{l}29.65 \\
35.97\end{array}$ & 1.21 & $(0.98,1.50)$ & $p=.0785$ \\
\hline Gender & $\begin{array}{l}\text { Male }^{*} \\
\text { Female }\end{array}$ & $\begin{array}{l}26.14 \\
29.38\end{array}$ & 1.12 & $(0.98,1.29)$ & $p=.0976$ \\
\hline Involved with criminal justice system & $\begin{array}{l}\text { Not involved* } \\
\text { Involved }\end{array}$ & $\begin{array}{l}32.21 \\
23.85\end{array}$ & 0.74 & $(0.63,0.88)$ & $p=.0005$ \\
\hline Lives alone & $\begin{array}{l}\text { No }^{*} \\
\text { Yes }\end{array}$ & $\begin{array}{l}25.51 \\
30.12\end{array}$ & 1.18 & $(1.03,1.35)$ & $p=.0168$ \\
\hline Number of recent psychiatric admissions & $\begin{array}{l}\text { None }{ }^{*} \\
1-2 \\
3 \text { or more }\end{array}$ & $\begin{array}{l}25.27 \\
26.97 \\
31.24\end{array}$ & $\begin{array}{l}1.07 \\
1.24\end{array}$ & $\begin{array}{l}(0.91,1.25) \\
(1.05,1.46)\end{array}$ & $\begin{array}{l}p=.4240 \\
p=.0110\end{array}$ \\
\hline Incapacity & $\begin{array}{l}\mathrm{No}^{*} \\
\text { Yes }\end{array}$ & $\begin{array}{l}21.28 \\
36.10\end{array}$ & 1.70 & $(1.47,1.95)$ & $p<.0001$ \\
\hline Any pain & $\begin{array}{l}\mathrm{No}^{*} \\
\text { Yes }\end{array}$ & $\begin{array}{l}30.47 \\
25.21\end{array}$ & 0.83 & $(0.68,1.01)$ & $p=.0576$ \\
\hline
\end{tabular}

Note. ${ }^{*}$ Reference category for ratio; ${ }^{* *}$ averaged over all levels of all other predictors; ${ }^{* * *}$ averaged over all levels of all predictors not involved in the interaction

Addressing IADL impairment early in a psychiatric admission may facilitate successful discharge and LOS optimization. It appears that in this general adult schizophrenia population, there is a "functional reserve" and with impairment in IADL function, that reserve is depleted and LOS is longer, possibly reflecting a greater difficulty getting and maintaining community placement. However, at least in this patient population, IADL function may be modifiable. One can speculate that in contrast, geriatric schizophrenia patients may already have an age-related depletion in "functional reserve" underscoring the longer LOS and the inabil- ity to be modified by function. Hence, impaired IADL function may have a lesser impact on LOS in this already impaired older population relative to the younger group. Further investigation of age-specific IADLs is warranted.

In both geriatric and general adult patients with schizophrenia, patients who live alone have an LOS $18 \%$ longer than those who do not live alone. In contrast, our previous mood disorder analysis found an association between living alone and longer LOS in geriatric but not adult mood disorder patients. ${ }^{[20]}$ In a large German analysis of a heterogeneous population of admissions to a psychiatric hospital, living 
alone was not associated with longer LOS. ${ }^{[28]}$ Living alone likely requires a higher level of functional independence, and it may be that functional deficiencies are more readily manifested in a younger schizophrenia population in comparison to younger mood disorder patients. Further, a heterogeneous analysis of mixed diagnosis patients may not detect diagnosis specific functional effects on LOS. Our finding may reflect a baseline functional deficit or a decrease in the aforementioned "functional reserve" in schizophrenia.

Length of stay in both study groups is predicted by number of recent psychiatric admissions. Patients with 3 or more recent admissions stay on average $24 \%$ longer $(95 \%$ CI: $5 \%-46 \%$ ) than those with no recent psychiatric admissions. Readmission is common in schizophrenia and the most robust predictor of future psychiatric hospitalization is the number of previous admissions, with unemployment and residential status also being significant contributors. ${ }^{[29]}$ In a study of 262 adults with schizophrenia or schizoaffective disorder, early readmission was associated with four or more previous hospitalizations $(85.7 \%$ vs. $57.7 \%, p=$ $.004)$, comorbid substance use disorder $(60.3 \%$ vs. $35.5 \%$, $p=.0006)$, major depression (40.6\% vs. $26.8 \%, p=.04)$, absence of a family meeting with inpatient staff (58.2\% vs. $41.8 \%, p=.02$ ), and prescription of a conventional rather than an atypical antipsychotic medication $(93.7 \% \mathrm{vs}$. $83.8 \%, p=.045) .{ }^{[30]}$ In our cohort, having 3 or more recent admissions in this patient population may be a marker of a more debilitating illness, resulting in a longer LOS.

Incapacity also predicted length of stay irrespective of study group. Patients with any incapacity stay on average $70 \%$ longer (95\% CI: 47\%-95\% longer) than those with no incapacities. Our finding in schizophrenia is consistent with our previous findings in mood disorders and in geriatric psychiatry patients as a whole $(20,21)$ as well as those in a systematic review of 41 studies. $^{[31]}$ In a study of legal reviews of treatment incapacity findings at 2 psychiatric hospitals in Ontario Canada, the average delay in initiating treatment when incapacity was contested was 25 days. However, if this finding was then taken to the courts, average treatment delay was 253 days. ${ }^{[32]}$ Incapacity has indirectly been associated with longer LOS on a geriatric psychiatry inpatient unit in a study of 384 patients. Requiring court proceedings to medicate against will increased the probability of having a LOS greater than 25 days 10 -fold, from $2.5 \%$ to $24.8 \%$ and led to a $65 \%$ increase in LOS. In this American study, researchers conclude that the financial burden of a slow moving legal system falls on providers of care who may or may not be able to share that burden with payers. ${ }^{[9]}$
The finding that involvement with the criminal justice system predicts shorter LOS likely reflects the path of forensic patients through the system. In this analysis, the amount of time spent in incarceration was not included in the LOS database and thus previous fitness assessments at CAMH or treatment in the criminal justice system may not have been captured in this analysis. Furthermore only 5 geriatric schizophrenia patients fell into this category (versus 197 adult schizophrenia patients) so the clinical relevance and applicability of this finding is unclear.

There are several limitations to this study. CAMH is a psychiatric hospital and while the results may be generalizable to psychiatric hospitals, the applicability to general hospital psychiatry is less clear. The decision to include only those patients who have already been discharged from CAMH over the 6-year period may also bias the results. We know that geriatric patients stay longer than younger patients and thus we may have eliminated more geriatric patients with extremely long LOS who have not yet been discharged compared to the adult controls. However, given the 6-year study duration, and the fact that these very long stay patients are extremely rare, we feel that the results do represent the vast majority of admissions for both adult and geriatric schizophrenia.

We have determined predictors of LOS in general adult and geriatric patients with schizophrenia that are part of the standard RAI assessment at 72 hours after admission. Increased impairment in IADLs predicts longer LOS in general adult but not in geriatric schizophrenia patients. Frequent recent psychiatric admissions, living alone and incapacity to make treatment decisions predict longer LOS in both adult and geriatric schizophrenia patients. Assessing predictors of LOS is significant for optimal management of inpatient resources, and understanding the factors that predict LOS may allow for prompt, targeted interventions that reduce LOS and improve overall access to the inpatient beds. Identifying factors associated with long LOS might also help to focus community resources on addressing these factors, both before and after hospitalization, also resulting in fewer and shorter stays.

\section{Acknowledgements}

This study was supported by the Government of Ontario AFP Innovation Fund.

\section{Conflicts of Interest Disclosure}

None of the authors report any conflicts of interest

\section{References}

[1] Lerner Y, Zilber N, ès Sc D. Predictors of cumulative length of psychiatric inpatient stay over one year: a national case register study. Israel Journal of Psychiatry and Related Sciences. 2010; 47(4): 304.

\section{PMid:21270504}

[2] Taiwo H, Ladapo O, Aina O, Lawal R, Adebiyi O, Olomu S, et al. Long stay patients in a psychiatric hospital in Lagos, Nigeria: original article. African journal of psychiatry. 2008; 11(2): 12832. PMid:19582331. http://dx.doi.org/10.4314/ajpsy.v11 


\section{i2. 30265}

[3] Masters GA, Baldessarini RJ, Öngür D, Centorrino F. Factors associated with length of psychiatric hospitalization. Comprehensive psychiatry. 2014; 55(3): 681-7. PMid:24387922. http://dx.doi .org/10.1016/j . comppsych.2013.11.004

[4] Tulloch AD, Khondoker MR, Fearon P, David AS. Associations of homelessness and residential mobility with length of stay after acute psychiatric admission. BMC psychiatry. 2012; 12(1): 121. PMid:22905674. Available from: http://data.worldbank.org /indicator/SH.XPD.PCAP

[5] McAlpine DD. Patterns of care for persons 65 years and older with schizophrenia. Schizophrenia Into Later Life: Treatment, Research, and Policy. 2003: 13.

[6] Roberts JS, Blow FC, Copeland LA, Barry KL, Van Stone W. Agegroup differences in treatment outcomes for male veterans with severe schizophrenia: a three-year longitudinal study. J Geriatr Psychiatry Neurol. 2000; 13(2): 78-86. Epub 2000/07/27. PMid: 10912729.

[7] Chung W, Chang H-S, Oh S-M, Yoon C-W. Factors associated with long-stay status in patients with schizophrenia: An analysis of national databases covering the entire Korean population. International Journal of Social Psychiatry. 2012: 0020764011431794.

[8] Sajatovic M, Popli A, Semple W. Ten-year use of hospital-based services by geriatric veterans with schizophrenia and bipolar disorder. Psychiatr Serv. 1996; 47(9): 961-5. Epub 1996/09/01. PMid: 8875661

[9] Blank K, Hixon L, Gruman C, Robison J, Hickey G, Schwartz HI. Determinants of geropsychiatric inpatient length of stay. Psychiatr Q. 2005; 76(2): 195-212. Epub 2005/05/12. PMid: 15884745.

[10] Mulsant BH, Stergiou A, Keshavan MS, Sweet RA, Rifai AH, Pasternak R, et al. Schizophrenia in late life: elderly patients admitted to an acute care psychiatric hospital. Schizophr Bull. 1993; 19(4): 709-21. Epub 1993/01/01. PMid: 8303222.

[11] Schultz SK, Miller DD, Oliver SE, Arndt S, Flaum M, Andreasen NC. The life course of schizophrenia: age and symptom dimensions. Schizophrenia Research. 1997; 23(1): 15-23. http://dx.doi .org /10.1016/S0920-9964(96)00087-4

[12] Cohen C, Vahia I, Reyes P, Diwan S, Bankole A, Palekar N, et al. Focus on geriatric psychiatry: schizophrenia in later life: clinical symptoms and social well-being. Psychiatric Services. 2008; 59(3): 232-4. PMid:18308900. http://dx.doi.org/10.1176/p s.2008.59.3.232

[13] Hopko DR, Lachar D, Bailley SE, Varner RV. Assessing predictive factors for extended hospitalization at acute psychiatric admission. Psychiatric Services. 2001; 52(10): 1367-73. PMid:11585954. http://dx.doi.org/10.1176/appi.ps.52.10.1367

[14] Anderson SW, Crist AJ, Payne N. Predicting inpatient length of stay with the expanded version of the brief psychiatric rating scale (Version 4.0). Psychiatric Services. 2004; 55(1): 77-9. PMid:14699205 http://dx.doi.org/10.1176/appi.ps.55.1.77

[15] Tulloch AD, Fearon P, David AS. Length of stay of general psychiatric inpatients in the United States: systematic review. Administration and Policy in Mental Health and Mental Health Services Research. 2011; 38(3): 155-68. PMid:20924662. http://dx.doi .org/10.1007/s10488-010-0310-3

[16] Mauri MC, Paletta S, Moliterno D, Colasanti A, Altamura CA. Depressive dimension, clinical outcome, and duration of hospitalization in acute schizophrenia. Asian journal of psychiatry. 2010; 3(3): 121-5. PMid:23051568. http://dx.doi.org/10.1016/j .ajp.2010.08.004

[17] Hirdes JP, Fries BE, Morris JN, Steel K, Mor V, Frijters D, et al. Integrated health information systems based on the RAI/MDS series of instruments. Healthc Manage Forum. 1999; 12(4): 30-40. Epub 2000/05/02. PMid: 10788069.

[18] Poss JW, Jutan NM, Hirdes JP, Fries BE, Morris JN, Teare GF, et al. A review of evidence on the reliability and validity of Minimum
Data Set data. Healthc Manage Forum. 2008; 21(1): 33-9. Epub 2008/09/26. PMid: 18814426.

[19] Smith TF, Hirdes JP. Predicting social isolation among geriatric psychiatry patients. Int Psychogeriatr. 2009; 21(1): 50-9. Epub 2008/10/31. PMid: 18959811. http://dx.doi.org/10.1017/S 1041610208007850

[20] Ismail Z, Arenovich T, Grieve C, Willett P, Sajeev G, Mamo DC, et al. Predicting hospital length of stay for geriatric patients with mood disorders. Can J Psychiatry. 2012; 57(11): 696-703. Epub 2012/11/15. PMid: 23149285.

[21] Ismail Z, Arenovich T, Grieve C, Willett P, Addington D, Rajji TK, et al. Associations of Medical Comorbidity, Psychosis, Pain and Capacity with Psychiatric Hospital Length of Stay in Geriatric Patients With and Without Dementia. International Psychogeriatrics. 2014 Oct 21: 1-9. [Epub ahead of print]. PMid:25330847.

[22] Doroud N, Akbarfahimi M, Ashayeri H, Khalafbeigi M. Comparative study of instrumental activities of daily living (IADLs) in patients with schizophrenia and normal matched individuals. Modern Rehabilitation. 2011.

[23] Bartels SJ, Mueser KT, Miles KM. Functional Impairments in Elderly Patients With Schizophrenia and Major Affective Illness in the Community: Social Skills, Living Skills, Behavior Problems. Behavior Therapy. 1997; 28: 43-63. http://dx.doi.org/10.10 16/S0005-7894 (97) 80033-0

[24] Lipskaya L, Jarus T, Kotler M. Influence of cognition and symptoms of schizophrenia on IADL performance. Scand J Occup Ther. 2011; 18(3): 180-7. Epub 2010/06/22. PMid: 20560806. http: //dx.doi.org/10.3109/11038128.2010.490879

[25] Nakanishi M, Setoya Y, Kodaka M, Makino H, Nishimura A, Yamauchi K, et al. Symptom dimensions and needs of care among patients with schizophrenia in hospital and the community. Psychiatry Clin Neurosci. 2007; 61(5): 495-501. Epub 2007/09/19. PMid: 17875027. http://dx.doi.org/10.1111/j.1440-1819.2007 $.01698 . \mathrm{x}$

[26] Umegaki H, Ando F, Shimokata H, Yamamoto S, Nakamura A, Endo $\mathrm{H}$, et al. Factors associated with long hospital stay in geriatric wards in Japan. Geriatrics and Gerontology International. 2003; 3: 120-7. http://dx.doi.org/10.1046/j.1444-1586.2003 $.00064 . \mathrm{x}$

[27] Roldan-Merino J, Garcia IC, Ramos-Pichardo JD, Foix-Sanjuan A, Quilez-Jover J, Montserrat-Martinez M. Impact of Personalized InHome Nursing Care Plans on Dependence in ADLs/IADLs and on Family Burden Among Adults Diagnosed With Schizophrenia: A Randomized Controlled Study. Perspectives in Psychiatric Care. 2012. PMid:23819667.

[28] Stevens A, Hammer K, Buchkremer G. A statistical model for length of psychiatric inpatient treatment and an analysis of contributing factors. Acta Psychiatrica Scandinavica. 2008; 103(3): 203-11. http://dx.doi.org/10.1034/j.1600-0447.2001.00043.x

[29] Schmutte T, Dunn CL, Sledge WH. Predicting time to readmission in patients with recent histories of recurrent psychiatric hospitalization: a matched-control survival analysis. The Journal of nervous and mental disease. 2010; 198(12): 860. PMid:21135635. http://dx.doi.org/10.1097/NMD.0b013e3181fe726b

[30] Olfson M, Mechanic D, Boyer CA, Hansell S, Walkup J, Weiden PJ. Assessing clinical predictions of early rehospitalization in schizophrenia. The Journal of nervous and mental disease. 1999; 187(12): 721-9. PMid:10665466. http://dx.doi.org/10.1097 /00005053-199912000-00003

[31] Kallert TW, Glockner M, Schutzwohl M. Involuntary vs. voluntary hospital admission. European archives of psychiatry and clinical neuroscience. 2008; 258(4): 195-209. PMid:18080170. http: //dx.doi.org/10.1007/s00406-007-0777-4

[32] Kelly M, Dunbar S, Gray JE, O’Reilly RL. Treatment delays for involuntary psychiatric patients associated with reviews of treatment capacity. Can J Psychiatry. 2002; 47(2): 181-5. Epub 2002/04/03. PMid: 11926081. 